\title{
MEMÓRIA NA MÚSICA DIGITAL: O SAMPLING DA OBRA DE ARTHUR VEROCAI
}

\section{Deivison Brito Nogueira*}

\section{RESUMO}

$\mathrm{O}$ artigo pretende discutir a maneira como disco homônimo do maestro e arranjador brasileiro Arthur Verocai (Continental, 1972) foi rejeitado pela gravadora, esquecido por mais de 30 anos e depois redescoberto e aclamado por DJs e rappers nacionais e estrangeiros que começaram a utilizar seus arranjos musicais como samples. Dois aspectos são importantes: o ressurgimento do disco em outro contexto cultural, procedimento da fruição da obra de arte como "obra aberta" e a característica hibrida que disco ganha na produção de novas linguagens pelo uso do sample. Os artigo busca: compreender como o disco ficou esquecido durante anos; verificar quais novos contornos a obra ganha pelo uso do sampling fora de seu contexto de criação e analisar como a transposição e a hibridização sonora gera inovações musicais. Os procedimentos metodológicos incluem pesquisa documental e bibliográfica. Utilizamos como referencial teórico de análise a semiótica da cultura, via Iuri Lotman, o conceito de obra aberta em Umberto Eco e o hibridismo cultural em Néstor García Canclini.

Palavras-chave: Música; Mídia; Memória; Arthur Verocai; Sampling

\section{INTRODUÇÃO}

Compreender o porquê de alguns elementos da cultura sumirem e outros permanecerem não é uma tarefa fácil. É necessário um estudo aprofundado de cada caso. No "senso comum" circula a máxima de que "o clássico um dia já foi $p \circ p$ ”, mas e quando um clássico vira $p o p$ sem ser percebido por sua geração após ser redescoberto décadas depois, com outros contornos, sentidos

* Universidade Metodista de São Paulo. Jornalista, Mestre em Comunicação Social pelo Programa de Pós-Graduação em Comunicação Social da Universidade Metodista de São Paulo (Pós-Com - UMESP). Membro do grupo de pesquisa Mídia, Arte e Cultura (MAC-CNPq). Bolsista do Conselho Nacional de Desenvolvimento Científico e Tecnológico - CNPq. E-mail: deivisong3@gmail.com deivison.nogueira@outlook.com 
e significados? Esse é o caso do disco homônimo do maestro e arranjador brasileiro Arthur Verocai de 1972. Um disco que, segundo especialistas, estava "à frente de seu tempo" mas que não recebeu o reconhecimento devido e por isso caiu num total esquecimento. Três décadas depois o disco reaparece nas mãos de DJs e rappers dos Estados Unidos e Europa como matéria-prima para a criação dos samples, isto é, as batidas utilizadas no rap e no hip hop. O artigo busca compreender como ocorreu essa reapropriação cultural e como o disco rearticula novos sentidos pelo uso do sample.

\section{UMA ABORDAGEM SEMIÓTICA PARA O ESTUDO DA CULTURA: A SEMIÓTICA DA CULTURA}

Os estudos que consolidaram a semiótica como disciplina e abordagem teórica tem sua origem na busca pelo sentidos dos signos presentes na cultura, na natureza e nas inúmeras linguagens criadas pelo homem. Desenvolvida nos anos 1960 por intelectuais russos da Universidade de Tártu-Moscou, a semiótica da cultura busca estudar os processos de troca de informações na relação "natureza/cultura". Por meio dos signos culturais é possível compreender os sistemas, códigos, linguagens, leis e convenções que o homem cria e usa para se comunicar. Alguns processos sígnicos criam suas próprias formas significação por meio dos complexos sistemas de decodificação da cultura. E a semiótica busca investigar essas diversas possibilidades dos sistemas culturais elaborarem seus modelos de significação e produção de sentido, que se encontram não apenas em um enunciado verbal, mas que produzem linguagem por meio de suas próprias manifestações.

\section{A CULTURA COMO UM GRANDE TEXTO: O CONCEITO DE TEXTO CULTURAL}

Um dos principais conceitos da semiótica da cultura é o conceito de texto cultural. Se nas correntes de estudos da semiótica, como a semiótica discursiva (greimasiana), o texto equivale a um enunciado escrito ou falado, para a semiótica da cultura, o texto tem um caráter ainda mais amplo. Ele pode ser compreendido como qualquer manifestação cultural capaz de gerar significados e de ser codificada enquanto linguagem, dotado de "um complexo dispositivo que guarda variados códigos, capazes de transformar as mensagens recebidas e de gerar novas mensagens" (MACHADO, 2003, p. 169).

O texto cultural possui três funções: comunicativa; geradora de sentidos e mnemônica. A primeira está atrelada à estrutura comunicativa da língua 
natural, utilizada para a transmissão de mensagens. Nessa concepção, o texto cultural apresenta-se homo-estrutural e homogêneo, expressão de uma única linguagem. Na função geradora de sentidos, o texto é heterogêneo e heteroestrutural. É representado na expressão de várias linguagens que quando decodificadas podem gerar novos sentidos. Até o "ruído" na comunicação mostrar-se não como um entrave, mas como possibilidade de gerar novos sentidos. Das três funções do texto cultural, a função geradora de sentidos é a que poderíamos chamar de função criadora e "se no primeiro caso, toda mudança de sentido no processo de transmissão é um erro e uma desfiguração, no segundo ela se converte em um mecanismo gerador de novos sentidos" (LOTMAN, 1998, p. 88).

A função mnemônica está relacionada à memória da cultura. Nela, o texto é capaz de preservar a lembrança de estruturas anteriores e de produzir novas linguagens no contato com outros textos, sem perder seu sentido original. A transformação da informação em texto ocorre com base nas três funções que o texto possui. Essa disposição multi-vocal do texto cultural seja "talvez o aspecto que mais caracteriza o que enfoque da semiótica da cultura e que a diferencia das demais disciplinas" (MACHADO, 2007, p. 31).

Do ponto de vista da semiótica da cultura, o disco de Arthur Verocai pode ser compreendido como um texto cultural, pois expressa características das três funções do texto. Num primeiro momento, o disco quando gravado tem uma função comunicativa e apresenta uma única linguagem, a linguagem instrumental (musical) do artista, em sua língua materna, de maneira homogênea e homo-estrutural. Num segundo momento, o disco é redescoberto por DJs e rappers e com a utilização do sample ele apresenta características da função geradora de sentidos, pois agora existem duas linguagens mútuas gerando diferentes sentidos do sentido original, de maneira heterogênea e hetero-estrutural. $\mathrm{O}$ disco ainda se constitui como um objeto de memória da cultura, pois o uso do sample o faz guardar características de estruturas sonoras anteriores sem perder seu sentido original.

Essa disposição em criar memória é uma "das propriedades mais desafiadoras dos textos culturais: o funcionamento como um espaço dotado de inteligência, que Lotman entende como 'mente' da cultura e, enquanto tal é capaz de fomentar operações imprevisíveis e explosivas" (MACHADO, 2013, p. 67). Nesse sentido, também é possível considerar o sample também como 
um desses "processos explosivos da cultura", processos que geram novas linguagens e novos textos culturais.

\section{O SAMPLE COMO GERADOR DE NOVOS TEXTOS CULTURAIS}

Iuri Lotman, semioticista russo, assevera que a maneira como os significados estão dados na cultura por meio dos signos, (códigos, linguagens e textos) só podem adquirir sentido dentro da semiosfera ${ }^{2}$. A semiosfera é o espaço fora do qual é impossível haver semiose, isto é, a produção de sentidos. Somente "dentro de tal espaço se tornam possíveis a realização de processos comunicativos e a produção de uma nova informação" (LOTMAN, 1998, p. 23). O encontro de novos sistemas de signos, ou semiosferas, geram novas informações, tornando esses espaços dialógicos por excelência. Dentro da semiosfera:

Acontece um processo dinâmico entre o centro, no qual ocorre a auto-descrição e o enrijecimento cultural, e a periferia, região de maior atividade semiótica, onde o contato entre outras culturas muito diferenciadas ocorre livremente. $\mathrm{Na}$ interação entre e centro e periferia se dá a renovação, o surgimento de novas formas culturais (MACHADO, 2007, p. 35).

O diálogo entre os sistemas periféricos e os sistemas centrais ocorre por meio da "fronteira" onde há o encontro entre diferentes culturas e que permite a interação dialógica entre diferentes semiosferas. A "fronteira" possui uma região de contato entre o espaço "extrassemiótico" e "interssemiótico" da semiosfera e funciona não "como um limite, mas como um filtro tradutor e responde pela produção de uma nova informação que passa a integrar o interior da semiosfera" (NUNES, 2011, p. 20), de modo que o que "parecia choque pode se transformar em encontro e resultar em produção de

\footnotetext{
1 A metáfora "explosão" possui relação com os processos culturais que modificam os sentidos e significados previamente estabelecidos, como no caso, o disco de Arthur Verocai. Para um maior aprofundamento do conceito, sugerimos a leitura do livro Cultura e Explosão de Iuri Lotman, publicado postumamente em 1999

2 Ambiente onde ocorrem os processos de significação cultural por meio dos signos. Para um melhor entendimento do conceito de semiosfera sugerimos a leitura dos três volumes do autor dedicados ao tema: La Semiosfera I, II e III, lançados pela Ediciones Cátedra, em Madrid, no fim da década de 1990 e início dos anos 2000 com tradução de Desiderio Navarro. A referência completa está inserida ao final deste artigo.
} 
inusitados sistemas de signos, códigos, textos e linguagens, isto é, em nova informação, reforçando o dinamismo, o dialogismo e o continuum cultural" (Ibidem, 2011, p. 20).

Uma produção cultural "marginal” inserida mais à periferia da semiosfera, como o sample no rap, é capaz de produzir suas próprias linguagens mediante à "fronteira" entre o jazz, o soul e a música instrumental presentes mais ao centro da semiosfera. Essas estruturas rígidas que se apresentam "relativamente estáveis" são chamadas de estruturas invariantes. Portanto, o trânsito entre diferentes linguagens na "fronteira" da semiosfera produz novos textos culturais que podem gerar novos sentidos pelo dialogismo entre os variados sistemas semióticos.

Nesse sentido, é importante considerar o que Mikhail Bakhtin chama de "excedente de visão estética", isto é, o modo como diferentes culturas reinterpretam-se de maneira dialógica. "O sentido só revela as suas profundezas encontrando e contando aos outros, o sentido do outro: entre eles começa uma espécie de diálogo que supera o fechamento e a unilateralidade desses sentidos, dessas culturas" (BAKHTIN, 2017, p. 19). Nesse encontro dialógico, essas diferentes culturas "não se fundem nem se confundem; cada uma mantém a sua unidade e a sua integridade aberta, mas ela se enriquecem mutuamente" (Ibidem, 2017, p. 19).

\section{O DISCO COMO "OBRA ABERTA"}

De acordo com o semioticista italiano Umberto Eco, uma obra de arte nunca possui um sentido fixo, ideal, da qual o artista se propôs a dar no processo de criação, ela ganha novos sentidos quando é posta ao público, por meio da fruição e da experiência estética. Uma mesma obra de arte pode ter conotações distintas para cada pessoa. Cada universo de sentidos cria suas próprias maneiras de significação. A sensação de incompletude e de inconclusibilidade de uma obra de arte permite ao público receptor recriar diferentes sentidos de um significado já dado.

O público, portanto, recria os sentidos ao reapropriar-se do conteúdo artístico e estético. Essa característica de abertura presente em toda a obra de arte "não reproduz uma suposta estrutura objetiva das obras, mas a estrutura de uma relação fruitiva; uma forma só é descritível enquanto gera a ordem de suas próprias interpretações" (ECO, 2010, p. 29). Ou seja, é nas mãos dos fruidores, das pessoas que se relacionam com os elementos artísticos, 
que obra de arte ganha seus sentidos mais profundos, o que Umberto Eco irá chama de "sistema de possibilidades".

As poéticas contemporâneas, ao propor estruturas artísticas que exigem do fruidor um empenho autônomo, frequentemente uma reconstrução do material proposto, refletem uma tendência geral de nossa cultura em direção àqueles processos em que, ao invés de uma sequência unívoca e necessária de eventos, se estabelece como que um campo de probabilidades, uma ambiguidade de situações, capaz de estimular escolhas operativas ou interpretativas sempre diferentes (ECO, 2010, p. 93).

Com as possibilidades de manipulação e recriação de sonoridades na música digital, DJs e artistas do rap e do hip hop utilizam a técnica do sampling. Trata-se de pequenos pedaços sonoros inseridos na criação de uma nova batida musical, originando assim o chamado sample. O recurso permite relacionar trechos de diferentes composições, distantes no tempo e no espaço, como um bricoleur. A técnica assemelha-se às colagens e as sobreposições das artes visuais da vanguarda europeia, como o Dadaísmo. $\mathrm{Na}$ era pós-moderna, no universo $p \circ p$ da cultura das mídias, ganham espaço manifestações culturais hibridas e transposições que geram diferentes linguagens e hibridizações, aquelas presentes na performance dos artistas nos videoclips e na música popular, difundida pelos meios de comunicação, como o rádio, televisão e internet.

\section{PROCESSOS HÍBRIDOS GERADORES DE NOVOS SENTIDOS}

Néstor García Canclini, antropólogo latino-americano, estuda os processos culturais híbridos na América Latina, as contradições da modernidade tardia e a relação entre culturas locais e globalizadas marcado pela desigualdade, tensões e a ascensão do neoliberalismo. A hibridização se cria por meio dos "processos socioculturais nos quais estruturas ou práticas discretas, que existiam de forma separada, se combinam para gerar novas estruturas, objetos e práticas" (CANCLINI, 2015, p. 19 - grifo do autor). Nem mesmo estas "práticas discretas", segundo o autor, podem ser consideradas puras. Por essa razão, García Canclini (2015, p. 22) questiona de que maneira "a hibridação funde estruturas ou práticas sociais discretas para gerar novas estruturas e novas práticas?"

A primeira condição para distinguir as oportunidades e os limites da hibridação é não tornar a arte e a cultura recursos para o realismo mágico da compreensão universal. Trata-se, antes, de colocá-los no campo instável, conflitivo, da tradu- 
ção e da "traição". As buscas artísticas são chaves nessa tarefa, se conseguem ao mesmo tempo ser linguagem e vertigem (CANCLINI, 2015, p. 40).

Canclini deixa clara sua posição antagônica a uma possível interpretação estandardizada das culturas latinas e das tentativas de centralidade e homogeneização, sobretudo da cultura norte-americana, nacionalista e globalizante. A produção artística latino-americana possui uma característica de reconhecimento e identidade, marcada por relações assimétricas de poder e que representam condições específicas de ser e de estar no mundo, onde a diferença adquire um caráter de unidade.

\section{ARTHUR VEROCAI E O DISCO DE 1972}

Arthur Cortês Verocai, à época com 27 anos, era maestro, arranjador e compositor.

Foi contratado pela gravadora Continental a pedido da cantora Célia, juntamente com o mastro Rogério Duprat, para produzir seus dois primeiros discos (1971 e 1972). Célia foi a grande incentivadora para o músico gravar o seu disco. Verocai ganhou notoriedade pelos trabalhos desenvolvidos nos discos de Célia até receber um convite para gravar um álbum autoral. "Eu fazia arranjo para a Célia na Continental, então, recebi um convite através dela, "olha, o pessoal da Continental quer que você faça um disco solo"'

A única condição posta pelo músico foi escolher o próprio time de instrumentistas e ter carta branca para fazer o disco que quisesse. Consta a participação de grandes nomes da música brasileira da época, como o baterista e percursionista Robertinho Silva, integrante do grupo Som Imaginário, o violonista e compositor Toninho Horta, parceiro do coletivo de músicos mineiros, Clube da Esquina. O disco de Verocai transita entre vários gêneros, desde o jaž, funk e o soul até o samba e a bossa nova, cheio de experimentação e sem nenhum tino mercadológico. A experiência adquirida como maestro e arranjador nos discos de Célia, Ivan Lins, Jorge Ben, Erasmo Carlos, Elizeth Cardoso, Gal Costa, Quarteto em Cy, MPB-4, O Terço, Guilherme Lamounier, Nélson Gonçalves e Marcos Valle fez do disco a materialização sonora das ideias que Verocai tinha na cabeça: uma obra experimental, hermética e à frente de seu tempo. A utilização de equipamentos e técnicas de gravação ainda pouco utilizadas em discos brasileiros tornou-o um símbolo de criatividade

Disponível em: < http://osomdovinil.org/arthurverocai/> Acesso em: 04 jul.2020 
e inovação musical. Os sintetizadores utilizados na faixa Caboclo, o ganho de mais um canal com o pedal wah-wah nas guitarras da faixa Presente de grego, o recurso de efeitos flanger nos arranjos de metais na faixa Karina (Domingo no Grajaú), técnicas de mixagem durante as gravações ao vivo, entre outras coisas tornaram o disco um marco de experimentalismo sonoro. Para Verocai:

O disco de 72 reflete uma busca e uma experimentação musical. Eu estava com um espírito bastante aventureiro nesse álbum e isso me levou a explorar novos caminhos para a melodia, harmonia e ritmo. Na música Sylvia, criei uma célula rítmica no violão junto com uma linha melódica. Adicionei bateria e percussão não convencionais, junto com uma leve orquestração de quatro flugelhorn e uma flauta, e um toque delicado das cordas (12 violinos, quatro violas e quatro violoncelos). Fiquei felicíssimo, achei que tinha feito uma coisa ótima, e no entanto caíram de pau em cima. ${ }^{4}$

Para sua surpresa, o trabalho não obteve a recepção esperada. A Continental, conhecida por gravar gêneros mais populares, como a música sertaneja, não sacou a ideia do disco e apenas distribuiu o LP nas lojas sem nenhum tipo de divulgação. Aborrecido com o resultado, Arthur ficou taxado de maluco por ter produzido um experimental, sem pé nem cabeça. "Eu virei maluco no disco do Ivan [Lins] e no meu eles carimbaram a maluquice. Aí eu virei um maluco beleza mesmo, porque depois que eu fiz esse disco instrumental eu fiquei taxado de louco" . A rejeição do disco gerou um impacto muito negativo na vida do artista. "Eu quase entrei em depressão. Foi uma fase difícil da minha vida. Guardei o vinil no armário e não ouvi mais por uns bons anos. Meu filho, quando começou a crescer, queria ouvi-lo e eu não deixava. Ficava aborrecido quando alguém o tocava"'

Nos anos seguintes, de acordo com dicionário Cravo Albin da música popular brasileira, Arthur Verocai trabalhou como arranjador e instrumentista nos discos de Gal Costa, Índia, 1973, Chico Buarque, Meus Caros Amigos, 1976, e Tim Maia, Tim Maia, 1976. Em 1983, abre seu próprio estúdio, "V/Casa do Som", no Rio de Janeiro, voltado ao mercado publicitário, na criação de jingles para comerciais TV e trilhas sonoras para o audiovisual. Trabalhou nas campanhas da Brahma, Coca-Cola, Sul América, Petrobras (Copa do Mundo

Disponível em: <http://almanaquecarioquice.com.br> Acesso em: 04 jul.2020.

Disponível em: < http://osomdovinil.org/arthurverocai/> Acesso em 04 jul.2020.

Disponível em: <https://www.bbc.com/portuguese/geral-45228749> Acesso em 04 jul.2020. 
de 1994 e 1998), Souza Cruz, Sorvete Sem Nome e a inauguração da Linha Vermelha no Rio de Janeiro. Como diretor musical, trabalhou na criação de trilhas sonoras e temas de abertura das novelas da Rede Globo de Televisão e no programa Som Livre Exportação?

\section{A REDESCOBERTA DO DISCO}

Alexandre Kassin, produtor musical e amigo de infância do filho de Arthur, Ricardo Verocai, estava passeando numa rua de lojas de discos em Tóquio, no Japão na década de 1990. Ao entrar na loja First Impressions, Kassin vê o disco de Verocai pendurado na parede em destaque. Perguntou ao dono da loja sobre o LP, ele disse que se tratava de uma obra raríssima e muito disputada nos Estados Unidos, Inglaterra e Japão por colecionadores e, sobretudo, por DJs e rappers. Até aquele momento, Kassin não sabia que Verocai havia gravado um disco autoral, também não imaginava que a obra havia adquirido todo aquele status. Kassin ainda relata a mesma experiência numa viagem que fez à Europa. Foi quando percebeu que se havia criado um culto em torno do disco de Verocai. Ao chegar ao Brasil, Kassin conta a Verocai o que ouviu do especialista japonês e das conversas com músicos e DJs europeus. Verocai custa a acreditar. "Pô, pelo amor de Deus, como? Aqui não aconteceu nada"s.

É interessante notar que nos anos 1980 e 1990, muitos produtores estrangeiros vinham ao Brasil procurar os discos raros e "obscuros" lançados no Brasil na década de 1970. Em uma dessas andanças, levaram milhares de discos para os Estados Unidos, Europa e Ásia onde eram vendidos para colecionadores e lojas especializadas. Um caso emblemático ocorreu com músico brasileiro Tom Zé quando David Byrne, ex-vocalista da banda americana Talking Heads, relançou em 1990 em seu próprio selo, Luaka Bop, o disco Estudando o Samba, de 1976, que obteve pouca ressonância no cenário da música brasileira. O disco The best of Tom Zé compilado por Byrne, traz as músicas dos discos Todos os olhos, 1973 e Estudando o Samba, 1976. A obra ficou entre os dez melhores discos da década de 1990 em todo o mundo, segundo a revista Rolling Stone ${ }^{10}$.

Disponível em: <http://dicionariompb.com.br/arthur-verocai/dados-artisticos> Acesso em 04 jul.2020. Disponível em: <http://osomdovinil.org/arthurverocai/>. Acesso em 04 jul.2020.

Felipe Vianna (2016, p. 99) classifica como "obscuro" os discos brasileiros mais cultuados e procurados.

10 Disponível em <http://dicionariompb.com.br/tom-ze> Acesso em: 05 jul.2020. 
Já o disco de Arthur Verocai tornou-se um item raríssimo e muito disputado por músicos e colecionadores em todo o mundo. Em 2012, uma cópia original de 1972 foi arrematado em um leilão virtual do eBay pela bagatela de US\$ 5.100, o equivalente a 20,000 R \$; o maior valor pago por um disco brasileiro na história. A primeira reedição do disco fora acontecer somente em 2003, 31 nos depois, pelo selo americano Ubiquity Records, depois em 2011, pelo selo holandês Kindred Spirits e por último no Brasil em 2012, pela Polysom, sua primeira reedição brasileira. Arthur Verocai conta que:

Na década de 90 o pessoal começou a me dizer que todo mundo gostava do disco na Europa. O Kassin, que é amigo do meu filho, veio uma vez da Europa e também falou comigo a mesma coisa. Tá bom então, legal. Aí em 2003 eles me contactaram por e-mail para lançar nos Estados Unidos. Foi aí que começou, porque a Ubiquity tem muita penetração nesse papo de música black, da música negra, do rbythm and blues ${ }^{11}$.

Um ano antes, em 2002, ele lança de maneira independente o disco Sandade Demais e divulga as músicas em um site. Foi por meio do site que "a gravadora americana Ubiquity me contatou querendo relançar o disco e aí eu falei: 'Então, vamos relançar o disco lá nos Estados Unidos' e isso gerou uma coisa muito legal, porque o pessoal de lá começou a curtir também. O pessoal do vinil começou a curtir e a samplear". Verocai conta que os DJs "pegavam as obras e mexiam nelas. Tiravam um som daqui, outro dali e trocavam de lugar, mexiam naquilo. Eles sampleavam a parte instrumental das músicas, as introduções, as voltas que tinham, as coisas orquestradas"12.

Um interessante levantamento feito pelo antropólogo e pesquisador Felipe Brandão em sua dissertação de Mestrado em Antropologia mostra uma relação de músicas utilizadas por DJs e rappers americanos e europeus em formato sample criadas entre os anos de 2004 e 2015. Os dados obtidos no portal "whosampled.com" trazem o total de 32 músicas sampleadas. A faixa $\mathrm{Na}$ boca do sol foi mais utilizada, ao lado de Dedicada e ela e Velho parente.

11 Disponível em: < http://noisey.vice.com/pt_br/blog/disquecidos-arthur-verocai-1972> Acesso em: 05 jul.2020.

12 Disponível em: <http://osomdovinil.org/arthurverocai/>. Acesso em 05 jul.2020. 


\begin{tabular}{|c|c|c|c|}
\hline $\begin{array}{l}\text { Ano de } \\
\text { lançamento } \\
\text { do sampler }\end{array}$ & $\begin{array}{l}\text { Música original } \\
\text { sampleada }\end{array}$ & $\begin{array}{l}\text { Música criada a partir } \\
\text { do sampler }\end{array}$ & Artista \\
\hline 2004 & "Seriado" & "Passion Flower" & Metal Fingers \\
\hline 2005 & "Na Boca do Sol" & "Orris Root Powder" & Metal Fingers \\
\hline 2005 & "Na Boca do Sol" & "Mindig Itt" & Bankos e Norba \\
\hline 2005 & "Caboclo" & "We Got Now" & Little Brother \\
\hline 2006 & "Pelas Sombras" & "Brazilliant Thought" & Dr. Who Dat? \\
\hline 2007 & "Na Boca do Sol" & “Zonin' Out” & Polyrhythm Addicts \\
\hline 2008 & "Na Boca do Sol" & "Do the right thing" & Ludacris \\
\hline 2008 & "Na Boca do Sol" & "Soul Position" & Almighty \\
\hline 2010 & "Na Boca do Sol" & "Put in Work" & ScHoolboy Q \\
\hline 2010 & "Na Boca do Sol" & "Freebie" & Curtis King \\
\hline 2010 & "Na Boca do Sol" & "Verocai" & Tae Beast \\
\hline 2010 & "Seriado" & "Règi Szleng" & Busa Pista \\
\hline 2011 & "Na Boca do Sol" & "You See It" & Curren\$y \\
\hline 2011 & "Na Boca do Sol" & $\begin{array}{l}\text { "Come Smoke With Me } \\
\text { Part 4" }\end{array}$ & Bow Wow e Snoop Dogg \\
\hline 2011 & "Na Boca do Sol" & "All Out" & Gracias e Joanna \\
\hline 2011 & "Na Boca do Sol" & "In the A" & Cyhi Da Prynce \\
\hline 2011 & "Dedicada a Ela" & "Perdido" & Brenk Sinatra \\
\hline 2012 & "Na Boca do Sol" & "Sunroof" & Curren\$y \\
\hline 2012 & "Na Boca do Sol" & "Lean" & Curren $\$ y$, Styles P e Fiend \\
\hline 2012 & "Na Boca do Sol" & "Chiraq Playaz" & King Louie \\
\hline 2012 & "Dedicada a Ela" & "La Cienega" & Da\$h, RetcH e Vince Staples \\
\hline 2012 & $\begin{array}{l}\text { "Presente de } \\
\text { Grego" }\end{array}$ & "Pick N Roll" & Curren\$y e Young Roddy \\
\hline 2012 & "Velho Parente" & "Arthur" & Dibiase \\
\hline 2013 & "Dedicada a Ela" & "The Spark" & $\begin{array}{c}\text { Statik Selektah, Action Bronson, } \\
\text { Joey Bada\$ } \$ \text { e Mike Posner }\end{array}$ \\
\hline 2013 & "Dedicada a Ela" & "Can't Get Out" & Curren\$y \\
\hline 2013 & "Dedicada a Ela" & $\begin{array}{c}\text { "Enemies All Around } \\
\text { Me" }\end{array}$ & Ghostface Killah \\
\hline 2014 & "Na Boca do Sol" & "Legacy" & $\begin{array}{l}\text { J. Rawls, John Robinson, Ceezar } \\
\text { e Lea Anderson }\end{array}$ \\
\hline 2014 & "Dedicada a Ela" & "Senseless Killin" & Your Old Droog \\
\hline 2014 & "Velho Parente" & $\begin{array}{l}\text { "The Sky Ain't the } \\
\text { Limit" }\end{array}$ & Mad Skillz e Bink \\
\hline 2014 & "Velho Parente" & "Velho (Freestyle)" & GoldLink \\
\hline 2015 & "Na Boca do Sol" & $\begin{array}{l}\text { "Vous Deux (Denzel } \\
\text { Washington)" }\end{array}$ & $\mathrm{K}-\mathrm{OS}$ \\
\hline
\end{tabular}

Tabela 1: BRANDÃO, Felipe. VINIL É ASSIM, É SORTE: Colecionismo, garimpo e obscuridade no mundo do vinil. Dissertação (Mestrado em Antropologia) - Instituto de Ciências Humanas e Filosofia, Universidade Federal Fluminense, Niterói, 2016. 


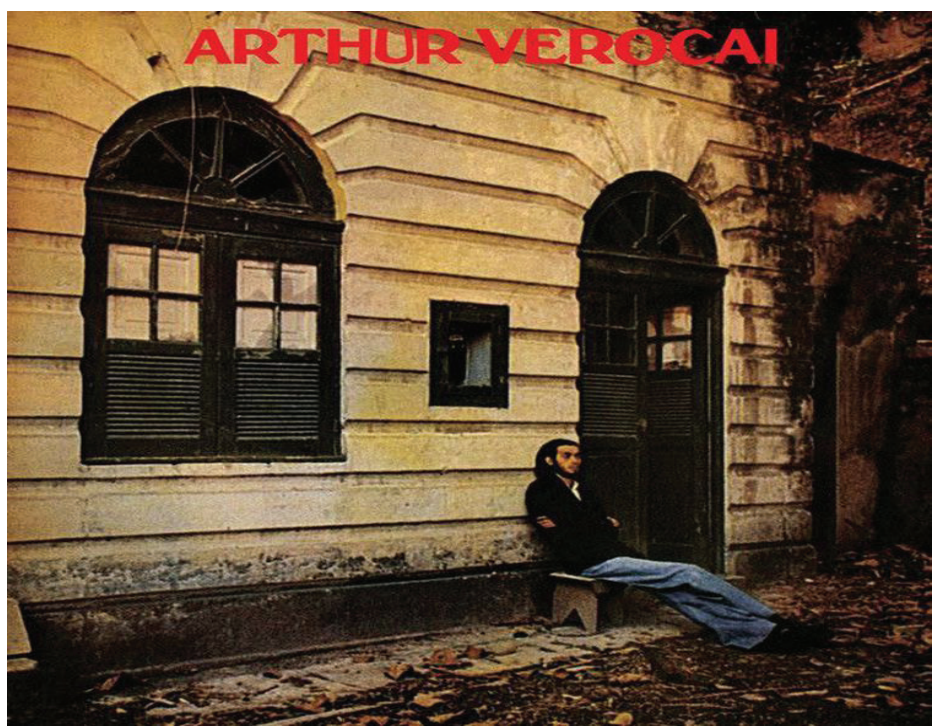

Figura 1: Capa do Disco de 1972. Fonte: http:// dicionariompb.com.br/arthur-verocai

Entre anos 2016 e 2018 consta o registro de mais 7 músicas sampleadas, desta vez, o primeiro registro de um artista brasileiro, o rapper e compositor baiano Baco Exu do Blues com a música $A$ pele em que habito. O sampler é derivado da música Dedicada a ela, faixa 5 do lado A do disco. Na boca do sol seguiu como a música mais utilizada, ao lado de Dedicada a ela e Velho parente respectivamente. No total, constam 39 músicas sampleadas desde a primeira reedição do disco pela Ubiquity Records nos Estados Unidos em 2003.

\begin{tabular}{|c|c|c|c|}
\hline $\begin{array}{c}\text { Ano de lançamento } \\
\text { do sampler }\end{array}$ & $\begin{array}{c}\text { Música original } \\
\text { sampleadas }\end{array}$ & $\begin{array}{c}\text { Música criada a partir } \\
\text { do sampler }\end{array}$ & Artista \\
\hline 2016 & "Na Boca do Sol" & "Alma do Sol & Abjo \\
\hline 2017 & "Na Boca do Sol" & "What we Been Thru" & Keys N Krates \\
\hline 2017 & "Na Boca do Sol" & "Início" & Space Gang \\
\hline 2017 & "Na Boca do Sol" & "The City" & "You Sound" \\
\hline 2017 & "Velho Parente" & $\begin{array}{c}\text { Indjnous Feat. Blue e Tanya } \\
\text { Morgan }\end{array}$ \\
\hline 2018 & "Dedicada a Ela" & "Plair, Nephew, Pleighboi & $\begin{array}{c}\text { Chris Craka feat. Vic Spen- } \\
\text { cer and Sulamani }\end{array}$ \\
\hline 2018 & "Dedicada a Ela" & "A Pele em que Habito" & Baco Exu do Blues \\
\hline
\end{tabular}

Tabela 2: Elaborada pelo autor a partir de dados obtidos no portal "whosampled". Fonte: http://www.whosampled.com/Arthur-Verocai/sampled. Acesso em 05 jul.2020. 


\section{CONSIDERACÕES FINAIS}

$\mathrm{O}$ disco de Arthur Verocai transita entre dois mundos: entre o apagamento e o ressurgimento. Mesmo na época em que foi lançado, o disco já sofria dificuldades de consolidar como um objeto da cultura. Uma reportagem da $B B C$ Brasil relata que a gravadora Continental à época passava por dificuldades financeiras. Então, pela baixa vendagem, decidiram recolher os discos de Verocai das lojas, derretê-los e utilizar a matéria-prima na produção de mais discos do Secos \& Molhados, grupo mais rentável da Continental à época. ${ }^{13}$. Esse talvez tenha sido um dos motivos do disco de Arthur Verocai ter ficado raro e quase impossível de se obter.

Somado a isso, a figura do arranjador musical constuma ter uma posição desprestigiada e sem o reconhecimento devido no processo de produção musical. A materia da $B B C$ traz um importante comentário do jornalista e musicólogo Zuza Homem de Mello sobre a figura do arranjador brasileiro que "em geral, ocupa uma posição menos destacada do que cantores e compositores, alem disso, há vários trabalhos na história que não alcançam a divulgação que merecem por falta de compreensão das pessoas em relaçao ao seu trabalho"14. Uma possível resposta à indagação feita no primeiro parágrafo deste artigo talvez sejam as dinâmicas em torno da produção de algumas linguagens e textos culturais e a maneira como desaparecem e reaparecem em um outro contexto cultural, com outros contornos, sentidos e significados. Talvez o disco não tenha obtido o sentido que o artista idealizara no momento de sua criação, mas como toda a obra de arte possui uma "abertura" para interpretação e recriação, é possível fazer dela coisas inimagináveis, como sample, por exemplo.

Essa abertura também foi responsável por reacender a discussão em torno de uma obra, que segundo o próprio autor, já havia morrido. O fato de retomar a discussão dos sentidos dos objetos culturais é ressignificá-los de alguma maneira, pois "se você tem de dizer algo novo, é porque o processo está transformando os significados que já estão lá. Portanto, cada ato de significação transforma o estado efetivo de todas as significações existentes" (HALL, 2018, p. 402). Por isso, o disco de Arthur Verocai, os elementos que os circundam, merecem uma pesquisa mais aprofundada, por se tratar de um produto cultural que rearticula sentidos de criatividade e inovação na música

Disponível em: https://www.bbc.com/portuguese/geral-45228749 Acesso em: 05 jul.2020.

14 Disponível em: https://www.bbc.com/portuguese/geral-45228749 Acesso em: 05 jul.2020 
brasileira, ao mesmo tempo em que contribui para a criação e conservação da memória da cultura, infelizmente ainda pouco [re]conhecido no Brasil, mas merecidamente cultuado e reverenciado por músicos e artistas em todas as partes do mundo.

\section{REFERENNCIAS}

BAKHTIN Mikhail. Estética da criação verbal. 2.ed. São Paulo: Martins Fontes, 1997.

BAKHTIN Mikhail. Notas sobre literatura, cultura e ciências humanas. São Paulo: Editora 34, 2017. BRANDÃO, Felipe. VINIL É ASSIM, É SORTE: Colecionismo, garimpo e obscuridade no mundo do Vinil. Dissertação (Mestrado em Antropologia) - Instituto de Ciências Humanas e Filosofia, Departamento de Antropologia, Universidade Federal Fluminense, Niterói, 2016.

ECO, Umberto. Obra aberta. 9.ed. São Paulo: Perspectiva, 2015.

GARCÍA CANCLINI, Néstor. Culturas híbridas: estratégias para entrar e sair da modernidade. 4.ed. São Paulo: Edusp, 2015.

HALL, Stuart. Da diáspora. Identidades e mediações culturais. Belo Horizonte: Ed: UFMG, 2018.

LOTMAN, Iuri. A estrutura do texto artístico. Lisboa: Editorial Estampa, 1978.

LOTMAN, Iuri. La Semiosfera I - Semiótica de la cultura y del texto. Madrid: Ediciones Cátedra, 1996.

LOTMAN Iuri. La Semiosfera II - Semiótica de la cultura y del texto, de la conduta y del espacio. Madrid: Ediciones Cátedra, 1998.

LOTMAN, Iuri. La semiosfera III - Semiótica de las artes y de la cultura. Madrid: Ediciones Cátedra, 2000.

LOTMAN, Yuri. Cultura y explosión. Lo previsible y lo imprevisible en los procesos de cambio social. Barcelona: Gedisa, 1999.

MACHADO, Irene. (org.). Semiótica da cultura e semiosfera. São Paulo: Annablume/Fapesp, 2003.

MACHADO, Irene. Escola de Semiótica: A experiência de Tártu-Moscou para o estudo da cultura. São Paulo: Ateliê Editorial/Fapesp, 2007.

MACHADO, Irene. Pensamento semiótico sobre a cultura. Revista Sofia (versão eletrônica). Espirito Santo, vol.2, n.2 agosto/2013, p. 60-72.

NUNES, Mônica Rebeca Ferrari. Passagens, paragens, veredas: semiótica da cultura e estudos culturais. In: SANCHES, Tatiana Amendola (org). Estudos culturais: uma abordagem prática: São Paulo: Ed. Senac, 2011. 